\title{
LXVI. On sonorous phænomena in electro-magnets
}

\section{J.P. Marrian}

To cite this article: J.P. Marrian (1844) LXVI. On sonorous phænomena in electro-magnets, Philosophical Magazine Series 3, 25:167, 382-384, DOI: 10.1080/14786444408645017

To link to this article: http://dx.doi.org/10.1080/14786444408645017

曲 Published online: 30 Apr 2009.

Submit your article to this journal $\pi$

Џll Article views: 2

Q View related articles $\sqsubset$ 
are not yet sufficiently numerous to allow of my venturing upon a description of them in this paper.

It is evident, therefore, that the cyanide of potassium and silver in a neutral state is a most excellent conductor of electricity. A little cyanide of potassium added does however facilitate its decomposition; and it is remarkable that when the cyanide of potassium added is in such proportion as to form a compound having two equivalents of cyanide of potassium to one of cyanide of silver, it is probably the most easily decomposed substance that we have. I have deposited silver from it easily with one square inch of copper and zinc immersed in water, the solution being at a temperature of $75^{\circ}$.

Another question suggested itself in connection with this salt, namely, the manner in which the cyanogen is transferred from the negative to the positive electrode, whether it travels direct, or is transmitted from particle to particle. Probably this has been answered satisfactorily long ago by other experimenters; but this being a salt eminently fitted to determine this question, I made the following experiment:-Into one division of the decomposition cell, a solution of pure cyanide of potassium and silver was introduced, and into the other division a neutral solution of chloride of potassium. By this arrangement, I considered that, if the cyanogen travelled direct, cyanide of silver should be formed upon the positive electrode which was immersed in the chloride of potassium; and if it was transmitted from particle to particle, chloride of silver would be deposited upon the pole and cyanide of potassium formed in the solution. The experiment verified this last supposition; after a current had passed through the solution for nearly eight hours the positive electrode was completely encased in a horny crust of considerable flexibility, which was not soluble in strong boiling nitric acid nor in hot sulphuric acid, and did not give off fumes of hydrocyanic acid on the addition of muriatic acid. 25 grains gave 18.6 of silver, which with the previous experiments is sufficient to prove the substance to be chloride of silver; the solution had the smell of cyanide of potassium, which had dissolved or decomposed a portion of the chloride of silver it held in solution.

LXVI. On Sonorous Phanomena in Electro-Magnets. By J. P. Marrian.

To the Editors of the Philosophical Magazine and Journal. Gentremen,

HAVING noticed a few phænomena resulting from magnetic influence in bars of soft iron, and which I have not before heard of, I am induced to submit an account of 
some experiments in the hope that they may lead to further investigation, as I am much inclined to think that many extraordinary facts may be gathered as well as important results obtained from a more extended prosecution of the subject. I have already made a great number of experiments, and shall proceed to detail a few of those which I consider to be the most interesting.

Having some considerable time since commenced a series of experiments on the conducting powers of different metals, among others I made use of several bars of soft iron, and found that when a bar of that metal is so circumstanced that it may be converted into an electro-magnet, at the instant that the magnetism is imparted $a$ sound is given from it, and another sound is again perceptible when the galvanic current is broken; the two sounds however are not exactly alike, but appear to correspond with such as may be produced by the alternate separation and attraction of the particles or certain particles composing the material acted upon. In order however that the subject may be more conveniently detailed, I will describe a few experiments.

I constructed a helix of thick copper wire, on the outside of which is another of a much thinner wire, with such an arrangement that they can be easily separated. I inserted a bar of soft iron one inch in diameter and twenty feet long in the compound helix, the primary wire of which I connected with a battery; on breaking the circuit a very audible sound was given from the iron, and again on forming contact. I then took bars of different dimensions, and varying in thickness from a quarter of an inch to two inches, and in length from six inches to twenty feet, and a sound was given by each, varying however in intensity; first, according to the size of the bar; second, to its diameter, filling or not filling the helix; third, the power of the battery; fourth, its position in the helix; for if the end were not placed beyond the centre of the primary coil no magnetic effects were produced, and the bar did not sound; and lastly, much appeared to depend on the state of the secondary coil, as the sounds diminished considerably on the ends being united, and the diminution was greater when the contact was metallic, than when $I$ held the wires in my hands. 'The sound produced was the tonic of each bar, and I could imitate it by striking the end of the bar with any metallic substance, but could produce no resemblance by means of a blow laterally. I used electrodes of different metals, and tried numerous experiments in order to prove that the sonorous effects were not produced by the jarring of the apparatus; one of these was the partial envelopment of the 
bar in wet clay and not suffering it to touch the helix, but the effect was still the same. I tried bars of silver, copper, zinc, tin, lead and brass, but no similar effect was produced.

In three bars of equal sizes, one of soft iron, one of hard steel, and the third a permanent magnet, no sensible difference in these effects could be detected.

These experinsents tend to prove that the particles of a bar of iron, when changing its electrical state, have a tendency decidedly motive, and that too along the bar in the direction of its axes. I have not yet been able to prove that any excitation in the same direction will induce an electric current (which I think is highly probable), but have put together these facts in a hurried manner, in order that we may have an opportunity of hearing of such investigation as we may naturally expect from the immense amount of talent employed in this interesting branch of science. I think also that these facts may serve to elucidate many others which I have not yet heard explained, but must reserve hypotheses for a future opportunity.

Birmingharn. Yours, very respectfully,

J. P. Marrian.

LXVII. Lines of Inquiry connected with the Theory of Agriculture. By Charles Daubeny, M.D., F.R.S., Professor of Rural Economy in the University of Oxford*.

I WILL now conclude by instancing a few lines of inquiry connected with the theory of agriculture, which nevertheless, from their intricacy, as well as from their having no direct bearing upon practice, do not seem of a nature to admit of being properly investigated, except it be upon an experimental farm.

The first of these relates to the power which plants possess of substituting one ingredient for another, as for example, soda for potass, lime for magnesia.

On this point we have at present some rather conflicting evidence. Saussure, for example, tells us, that firs from two different soils contain different earthy constituents, although the sum total was as nearly as possible the same; and Berthier has reported similar results as obtained by himself. In these instances lime seems to have replaced potass, soda and magnesia, whilst in other cases an inorganic acid appears to have been substituted for an organic one, as the sulphuric acid in opium for the meconic.

* Extracted from the author's "Lecture on Institutions for the better Education of the Farming Classes, especially with reference to the proposed Agricultural College near Cirencester, \&c. Delivered at the Botanic Garden, Oxford, on Tuesday, May 14, 1844." Oxford, 1844, 8vo. 